\title{
Relative Biological Effectiveness
}

National Cancer Institute

\section{Source}

National Cancer Institute. Relative Biological Effectiveness. NCI Thesaurus. Code C94971.

A factor assigned to a type of ionizing radiation in converting absorbed dose measured in grays to a biologically equivalent dose measured in sieverts. In formula form, (equivalent dose $)=($ quality factor $) \times($ absorbed dose $)$. 